\title{
The Comprehensive Evaluation of the National Higher Education System Based on EWM and ARMA Models
}

\author{
Li-Jun Xu $\mathbb{D}^{1},{ }^{1}$ Yan Liang $\mathbb{D}^{2},{ }^{2}$ Jin-Tao Su $\mathbb{D}^{2},{ }^{2}$ Tong Ouyang $\mathbb{D}^{2}$, and Jia-Ming Zhu $\mathbb{D}^{3}$ \\ ${ }^{1}$ School of Finance and Business, Shanghai Normal University, Shanghai 200234, China \\ ${ }^{2}$ Institute of Finance, Anhui University of Finance and Economics, Bengbu 233030, China \\ ${ }^{3}$ School of Statistics and Applied Mathematics, Anhui University of Finance and Economics, Bengbu 233030, China \\ Correspondence should be addressed to Jia-Ming Zhu; zhujm1973@163.com
}

Received 11 March 2021; Revised 22 March 2021; Accepted 31 March 2021; Published 26 April 2021

Academic Editor: Shenggang Li

Copyright (C) $2021 \mathrm{Li}$-Jun Xu et al. This is an open access article distributed under the Creative Commons Attribution License, which permits unrestricted use, distribution, and reproduction in any medium, provided the original work is properly cited.

Different countries have different education systems and their advantages and disadvantages. It is necessary to optimize their own higher education system and formulate policy plans to fully realize the optimization of the higher education system. For this reason, we propose to establish a continuous evaluation model of higher education health. This study mainly uses principal component analysis (PCA) and entropy weight method (EWM) to determine the evaluation model of higher education health status and makes autoregressive moving average model (ARMA) time series analysis based on the higher education evaluation model, which is obtained by studying long-term trends. The future development of education realizes the evaluation of sustainability. For Vietnam, that needs to be adjusted, the evaluation indicators based on the health status of the higher education system in developing countries will be added, tested, and adjusted and combined with the ARMA model prediction to determine the time period for the policy to meet reasonable expectations, and targeted development policies are proposed. Finally, we test the sensitivity of the established model, evaluate and analyze the advantages and disadvantages of the model, And combine the full text analysis to get the final conclusion.

\section{Introduction}

Under the current trend of world development, higher education system has become the focus of attention. Different countries have different educational systems, and their higher education systems have their own advantages and disadvantages. Under the influence of the new crown pneumonia, these countries have time to think about what kind of higher education system is better and feasible and to formulate policy plans for optimizing their higher education system in order to fully realize the optimization of their higher education system. However, it is very difficult to achieve the reform of higher education policy, which requires long-term persistence and great efforts.

In view of the present situation of higher education, this paper studies the following problems: (i) use relevant data to evaluate the health status of higher education system in any country, (ii) quantitative analysis and selection of countries where higher education systems need improvement, using relevant data, (iii) propose a reasonable vision for the future of our chosen country in the construction of higher education, (iv) measure the health status of higher education in the country based on relevant data and develop a healthy and continuous model system for it, (v) bring the country's higher education system to its intended state and propose targeted education policies and a timeline for their implementation, (vi) quantitative analysis of the effectiveness of our proposed educational policies through data, and (vii) analysis of the impact of policy plans on the real world in the process of implementation and the final outcome.

\section{Literature Review}

For the establishment of the national higher education system evaluation system, many experts and scholars have carried out more in-depth academic research in the field of 
national higher education. In order to better evaluate the higher education system in various countries, some representative documents are referred to and summarized as follows.

Liu Tong [1], aiming at the problem of too much emphasis on results and low credibility in educational evaluation, puts forward the integration of educational evaluation and block chain technology, combs the relevant application of block chain technology in the process of learning evaluation on the basis of theoretical analysis, and innovatively proposes to combine block chain technology with learning evaluation to ensure that the evaluation is true, accurate, and sustainable, in order to provide new ideas for the exploration of learning evaluation in higher education.

Wang [2] believes that the United Kingdom has introduced the concept of risk into the quality assessment of higher education in recent years, forming a higher education review evaluation based on the concept of risk, highlighting three aspects: risk as the basis, optimizing the process of quality risk assessment, and paying attention to the followup action of evaluation. It is its essential characteristic and management idea to carry out classified evaluation based on the possibility of college risk, to take quality improvement as the goal, to guide colleges and universities to form internal quality risk culture, and to implement the differential evaluation strategy of quantitative genre clothing.

Zhao [3] believes that the most important internal and external key factors affecting the sustainable development of higher education in China are the distortion of educational concepts such as the development of colleges and universities with light connotation, the extension of expansion, and the industrialization and utilitarianism of education. Colleges and universities should make efforts to maintain their internal advantages, construct the operating mechanism of the sustainable development of higher education, and perfect the supervision mechanism of the sustainable development of higher education.

Li [4] collected the national input and output data of higher education in 16 years before and after enrollment expansion and used the superefficiency DEA model to evaluate the efficiency of higher education input and output before and after enrollment expansion. The results show that the efficiency of higher education in China remains excellent after expanding enrollment. On the whole, the level of inputoutput efficiency of higher education in China is decreasing.

\section{Basic Assumptions}

In order to solve the problem, we make assumptions as follows: (i) assume that the data we have collected on higher education in each country are true and reliable, (ii) assume that the model we have developed can reasonably evaluate the development of higher education systems in each country, (iii) assume that our model is established according to the exact steps, and there is no human error, (iv) assume that the various higher education analysis indicators we have selected have practical significance, and (v) assume that the error of the model can be controlled within a reasonable range and the impact on the analysis results is limited.

\section{Analysis of Solving Educational Health and Sustainability Models}

\subsection{Evaluation of Higher Education System Based on Principal Component and Entropy Method}

4.1.1. Research Thought. First of all, any country is specifically divided into two categories: developed and developing. And, on this basis, the national higher education system has been defined. Specifically, we use 12 secondary and 5 primary indicators as a measure of the health and sustainability of the national higher education system. And, 12 secondary indicators are graduate enrollment (GEN), number of institutions of higher learning (RUN), number of full-time teachers (TN), enrollment in general institutions of higher learning (RSN), number of students in institutions of higher learning (RNI), college graduates (RGI), graduate student enrollment (PON), number of students studying abroad (ASN), funding for education (EM), state financial funding for sex education (FEE), graduation rate (GR), and employment rate (ER). Corresponding to the five primary indicators are cost of education (ES), educational opportunities (EC), education quality (EQ), educational exchange (EE), and education funds (EF). The classification diagram of the index system is shown in Figure 1.

Then, on the basis of 12 secondary indexes and five primary indexes, the corresponding data processing is carried out. In particular, five primary indexes are obtained by using principal component analysis model to reduce the dimension of the data index. On this basis, the entropy weight model is used to calculate the expression of the national higher education evaluation model.

4.1.2. Analysis Procedure. First, the 12 indexes of the model are tested by KMO and Bartlett test, which are shown in Table 1 . The results show that the significance level of the 12 indexes of the model is high, then each index passes the significance test of the model, and the index of the model can be further analyzed [5-9].

Secondly, the total variance interpretation is calculated by the 12 indexes, in which the cumulative variance interpretation of components 1 to 5 is 90.082 , which means that the first five principal components can explain the total variance of $90.082 \%$ of the 12 components. Therefore, the first five principal components can be extracted as the index after dimension reduction.

In order to determine the extracted principal component index more reasonably, the factor analysis gravel map is made for the 12 indexes, as shown in Figure 2.

In the factor analysis lithotripsy, the longitudinal axis represents the eigenvalue, the transverse axis represents the component, and the steep part of the eigenvalue is large, which contains more information. The broken lines of factors 1, 2, 3, 4, and 5 in Figure 2 are steep, and the discount behind them is relatively smooth and tends to be straight, and the first five factors can be extracted as common factors. In the component diagram, in a solid component, a more dense index can be used as the component to explain other 


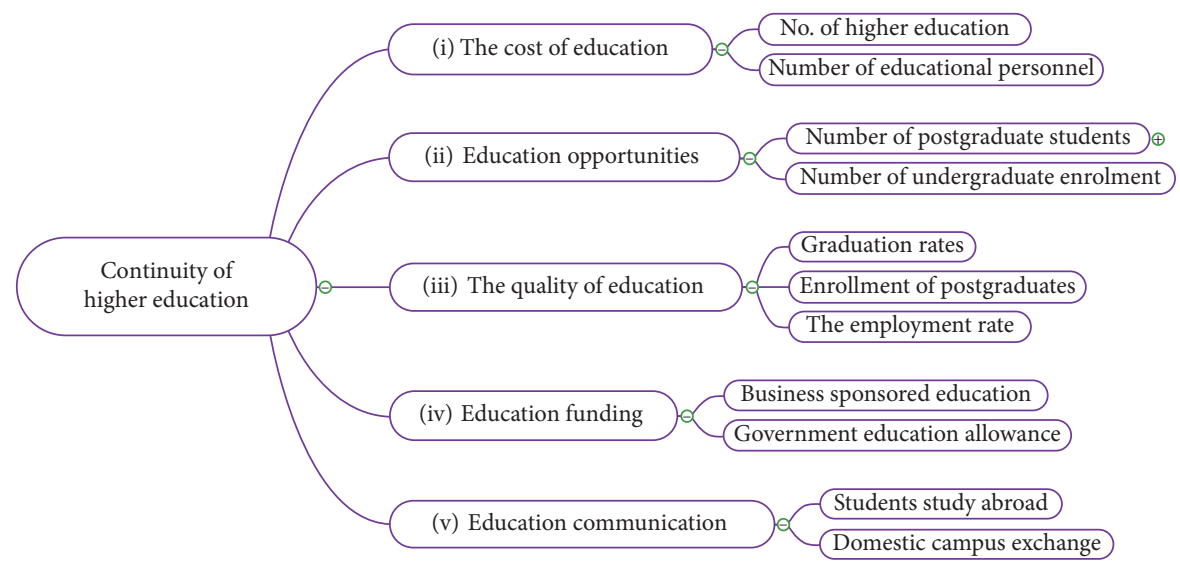

FIGURE 1: Classification of higher education system indicators.

TABLE 1: Total variance explanation.

\begin{tabular}{|c|c|c|c|c|c|c|}
\hline \multirow{2}{*}{ Constituent } & \multicolumn{3}{|c|}{ Initial eigenvalue } & \multicolumn{3}{|c|}{ Extract the square sum of the load } \\
\hline & Total & Variance percentage & Cumulate (\%) & Total & Variance percentage & Cumulate (\%) \\
\hline 1 & 6.299 & 74.828 & 74.828 & 6.299 & 74.828 & 64.828 \\
\hline 2 & 2.170 & 9.753 & 84.581 & 2.170 & 9.753 & 84.581 \\
\hline 3 & 1.437 & 3.640 & 88.222 & 1.437 & 3.640 & 88.222 \\
\hline 4 & 0.558 & 1.681 & 89.902 & 0.558 & 1.681 & 89.902 \\
\hline 5 & 0.122 & 0.180 & 90.082 & 0.122 & 0.180 & 90.082 \\
\hline 6 & 0.057 & 0.055 & 91.937 & - & - & - \\
\hline 7 & 0.024 & 0.034 & 93.971 & - & - & - \\
\hline 8 & 0.002 & 0.021 & 94.992 & - & - & - \\
\hline 9 & 0.001 & 0.006 & 97.998 & - & - & - \\
\hline 10 & 0.000 & 0.002 & 99.999 & - & - & - \\
\hline 11 & $3.380 E-5$ & 0.000 & 100.000 & - & - & - \\
\hline 12 & $3.365 E-5$ & 0.000 & 100.000 & - & - & - \\
\hline
\end{tabular}

indicators, and the component score coefficient matrix is calculated. The index with the largest score coefficient is extracted from the five components as the final principal component index. The component score coefficient matrix is shown in Table 2.

After determining the five main principal component indicators, use the entropy method on the five main indicators to obtain the weight between the five indicators. The results are shown in Table 3 [10-12].

The entropy value is a physical measurement unit. At the same time, the larger the entropy value is, the more chaotic the data are, the less information the data carry, the smaller the utility value is, and the smaller its weight is. Furthermore, the entropy law is a research method that combines the information value provided by the entropy value to determine the weight. This method describes the basic principle and analysis process of the entropy value, conducts an indepth description and analysis of the final weight value, and finally analyzes the results summarized to draw conclusions.

We integrated the weights of five first-level indicators: education cost (ES), educational opportunity (EC), education quality (EQ), educational exchange (EE), and

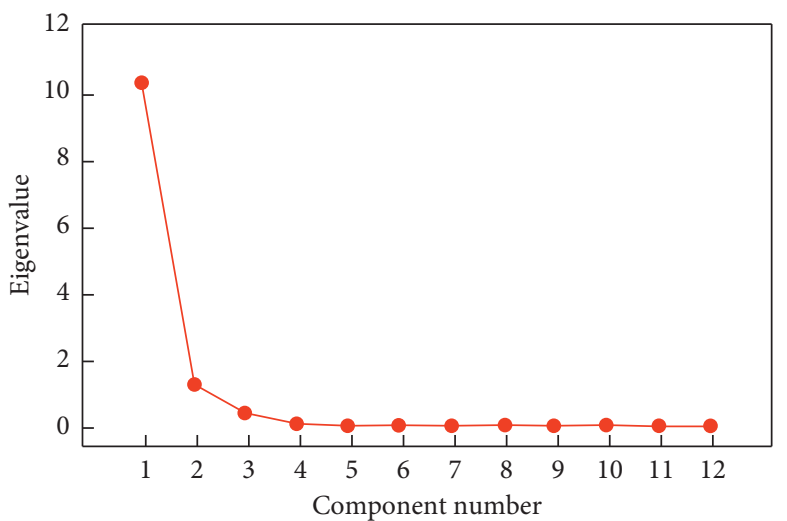

Figure 2: Gravel diagram.

educational funds (EF), and finally, we obtained the country's higher evaluation mathematical model of the health of the education system as follows:

$$
\begin{aligned}
\mathrm{EH}= & 0.3729 \mathrm{ES}+0.1641 \mathrm{EF}+0.1561 \mathrm{EE} \\
& +0.1754 \mathrm{EC}+0.1314 \mathrm{EQ},
\end{aligned}
$$


TABle 2: Composition score coefficient matrix.

\begin{tabular}{lccccccccccccc}
\hline Ingredient & GEN & RUN & TN & RSN & RNI & RGI & PON & ASN & EE & FEE & GR & ER \\
\hline 1 & 0.087 & 0.096 & 0.086 & 0.095 & 0.084 & 0.091 & 0.082 & 0.094 & 0.093 & 0.092 & 0.045 & -0.068 \\
2 & -0.04 & -0.05 & -0.035 & -0.158 & -0.09 & 0.022 & 0.017 & 0.107 & 0.142 & 0.171 & 0.674 & 0.548 \\
3 & 0.108 & -0.276 & -0.189 & -0.135 & -0.163 & -0.197 & 0.184 & 0.56 & 0.51 & 0.46 & -0.91 & 0.618 \\
4 & 0.588 & 0.769 & 0.908 & 2.745 & 0.842 & 0.847 & 0.534 & -1.114 & -1.06 & -1.309 & -0.959 & 2.101 \\
5 & -3.261 & 2.375 & 1.332 & -0.059 & 0.787 & 1.718 & -4.553 & 0.307 & 0.829 & 1.462 & -0.868 & 0.581 \\
\hline
\end{tabular}

TABLE 3: Weight calculation results of the entropy method.

\begin{tabular}{|c|c|c|c|c|c|}
\hline Item & ES & $\mathrm{EF}$ & $\mathrm{EE}$ & $\mathrm{EC}$ & EQ \\
\hline Information entropy $e$ & 0.8732 & 0.9442 & 0.9469 & 0.9403 & 0.9553 \\
\hline Information effect value $d$ & 0.1256 & 0.0558 & 0.0531 & 0.0597 & 0.0447 \\
\hline Weight coefficient $w(\%)$ & 37.29 & 16.41 & 15.61 & 17.54 & 13.14 \\
\hline
\end{tabular}

where $\mathrm{EH}$ is an evaluation indicator of the health status of the national higher education system, and ES, EC, EQ, EE, and EF are five indicators.

\subsection{Application of the Country's Higher Education Health} Evaluation Model. In order to apply the established model for assessing the health of the national higher education system to several countries, we choose two developed countries, Germany and the United States, and two developing countries, China and Vietnam, respectively, as the application object of the model.

By collecting and sorting out four countries' data on education costs, educational opportunities, education quality, educational exchanges, and educational funds and substituting them into the health assessment model of the national higher education system, we have obtained education details among different countries. The results of health evaluation form and the higher education health status difference table are shown in Table 4.

Table 4 only intercepts the education and health evaluation score data of different countries from 2015 to 2019 for display. Collect and sort out data on education costs (ES), educational opportunities (EC), educational quality (EQ), educational exchanges (EE), and educational funds (EF) in the four countries of the United States, Germany, China, and Vietnam. And, substitute the corresponding data into the higher education health status evaluation model, and then, get the trend of the higher education health status of each country in the past 30 years. The trend chart is shown in Figure 3.

From this trend, we can know that the higher education systems in the United States and Germany are in good health and have strong growth sustainability, while the development of China's higher education systems closely follows the development trends in the United States and Germany. There was a rapid growth in the year. Finally, Vietnam's higher education system has been lagging behind the world average. At the same time, in recent years, the gap between the country's higher education development and other countries has grown wider, and its higher education development level has clearly lagged behind in other countries in the world.
TABLE 4: Educational health evaluation form.

\begin{tabular}{lcccc}
\hline Time (year) & India & Germany & America & China \\
\hline 2015 & 2.45408 & 6.98188 & 6.51304 & 5.47677 \\
2016 & 2.13845 & 6.59453 & 6.58271 & 6.24751 \\
2017 & 3.49031 & 7.78353 & 7.70436 & 7.40032 \\
2018 & 3.19008 & 7.12173 & 7.49301 & 7.51723 \\
2019 & 4.24307 & 9.21407 & 9.15005 & 7.25357 \\
\hline
\end{tabular}

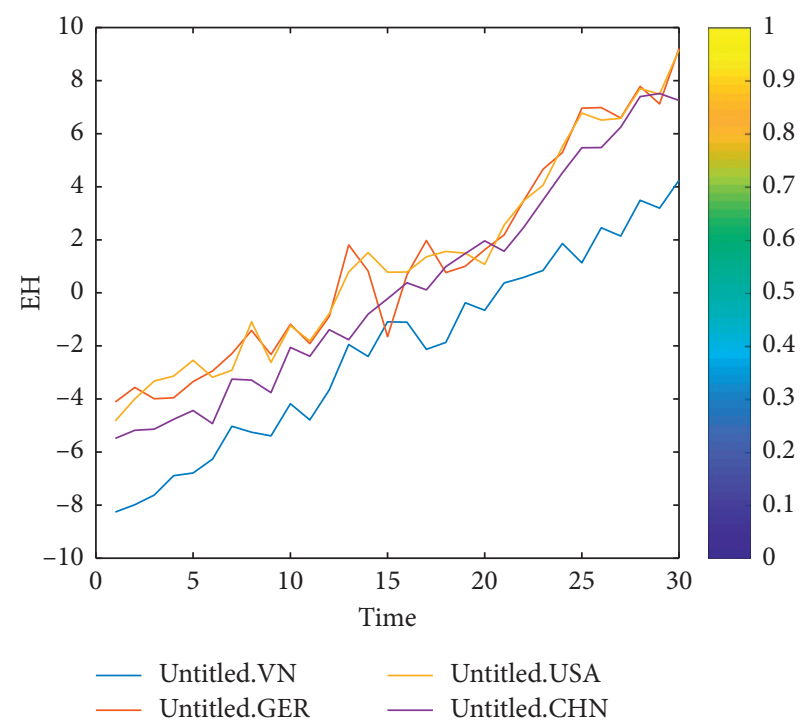

FIGURE 3: Evaluation of the health status of higher education in four countries.

For this reason, we believe that Vietnam's higher education system still has a lot of room for improvement. As a whole, Vietnam's higher education system lags behind the world average, and there is still a lot of room for improvement in the development and sustainability of its educational health.

4.3. A Reasonable Vision for the Construction of Higher Education in Vietnam. Through the established higher education system health evaluation model, we can know that the development status of higher education in Vietnam needs to be improved. For the improvement vision of higher 
education in Vietnam, we have carried out concrete development from the five aspects of the health of higher education in Vietnam. They are based on the five indicators in the established model: educational cost (ES), educational opportunity (EC), educational quality (EQ), educational exchange (EE), and educational funds (EF). An achievable development vision is in line with the actual development of Vietnam in the future.

\subsubsection{Analysis of Vietnam's Higher Education Development} Vision. First, calculate the expected values of the health of higher education in several typical developing countries in the world in 2020, then average them to get a basic value, which is the average health of higher education in developing countries, the development trend and development speed of education health in developing countries, adjust the basic value, and obtain the expected value of higher education health. Here, we omit the solution process, and the solution flowchart is shown in Figure 4. In the end, the expected value of Vietnam's higher education health is 8.3, and the improvement vision is to reach the average higher education health of developing countries that year.

\subsubsection{Research on the Subindices of Vietnam's Higher Ed-} ucation Development Vision. Through the establishment of the model, we can get the development status of five indicators in China, Vietnam, Germany, and the United States in the past 30 years. The results are shown in Figure 5.

\section{(1) Vietnam's Development Vision for Higher Education} Costs. Through the time series diagram, we can intuitively find that the cost of education in China and the United States has gradually increased over time, and the cost of education in China has risen faster than that in the United States. This is mainly due to China's large population base and high education costs. On the contrary, Vietnam's education cost has hardly changed in the past 30 years and has been at a relatively low level compared to developed countries such as the United States and Germany. The reason for this phenomenon is mainly due to the lack of human resources and material resources invested by the Vietnamese government in education construction, that is, the lack of teachers and infrastructure, which has led to the severely low education costs in Vietnam. Although low education cost is a good thing, too low education cost will cause educational resources and facilities to fail to keep up with the requirements of educational development.

Regarding the development vision of Vietnam's higher education system in terms of education costs, the Vietnamese Ministry of Education should keep higher education costs as high as possible on the basis of making higher education costs meet the basic requirements for the development of education standards and raise higher education costs. The expenditure of education funds can significantly improve the educational development level and quality of the country's higher education, while the cost of higher education maintains a certain level of growth so that the growth effect of higher education costs can be effectively brought into play.

(2) Vietnam's Development Vision for Higher Education Opportunities. The time series chart of educational opportunities in the four countries obtained through the establishment of the model shows that, in the past 30 years, the educational opportunities of the four countries of the United States, Germany, Vietnam, and China have increased. Among them, developing countries such as China, the growth rate with Vietnam is relatively fast. At the same time, among the four countries, the fastest growing country in higher education opportunities is Vietnam, but its educational opportunities are still at a low level compared with other countries. This reflects that although Vietnam has achieved a steady growth rate in terms of educational opportunities in the past relative to its own country, there is still a large gap compared with other developed and developing countries. The main reason is that there is a big difference between the opportunities for enrolling in higher education in Vietnam and the opportunities for receiving education in higher education. This is closely related to the relationship between Vietnam's own higher education in terms of gender, region, ethnicity, and class.

Regarding the development vision of Vietnam's higher education system in terms of educational opportunities, we believe that Vietnam's education sector can continue to provide its citizens and major universities with more higher education opportunities. At the same time, the enrollment threshold and admission system of higher education in the country need to be further improved to increase the opportunities for higher education in Vietnam at the macrolevel and the opportunities in the process of receiving education at the microlevel, so as to enable more citizens are able to enjoy the educational opportunities of higher education, in order to improve the level of educational opportunities in the country, so as to meet the vision of the development of higher education opportunities.

(3) The Development Vision of Vietnam's Higher Education Quality. For the research on the quality of higher education in four countries, the data we use is the number of college graduates in each country. In the following time-series chart, we can find the rate of increase in the quality of education in China over time the faster it is, and the reason is that China's population base is much higher than the other three countries, so the number of college graduates is large. If we take the number of college graduates of the unit as the standard, we find that the quality of education in the United States is the highest and that in Vietnam is the lowest. The low quality of education in Vietnam is mainly due to the low efficiency of education management, backward teaching methods, and weak teachers.

Regarding the development vision of Vietnam's higher education system in terms of education quality, we believe that the late construction of major universities in Vietnam and the relatively limited number of enrollment expansion in universities have led to the increase in the quality of Vietnamese higher education in recent years. More limited, 


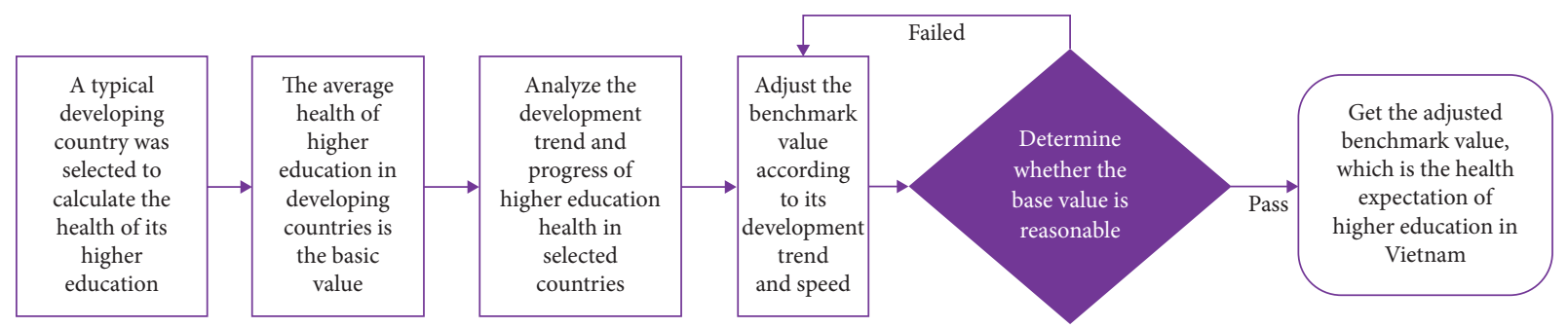

FIgURE 4: The flowchart of solving the expected value of the health of higher education in Vietnam.

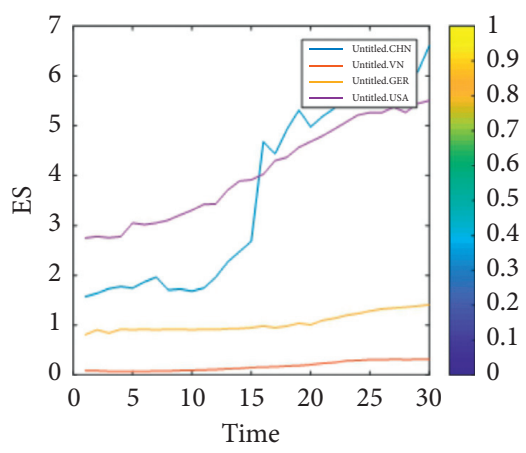

(a)

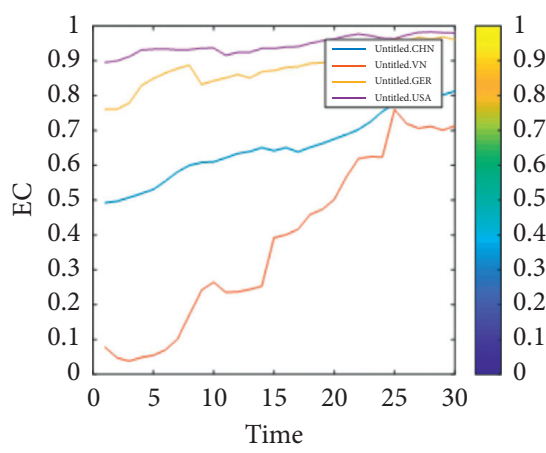

(b)

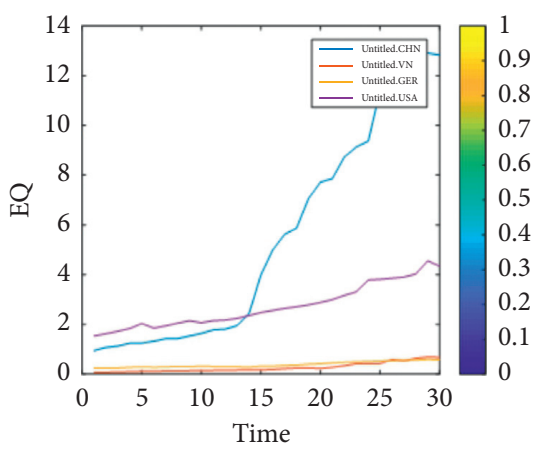

(c)

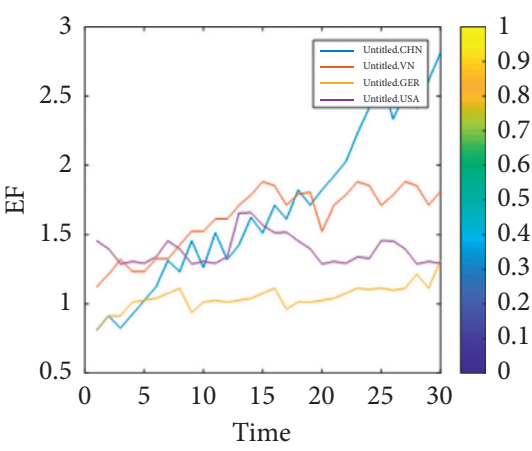

(d)

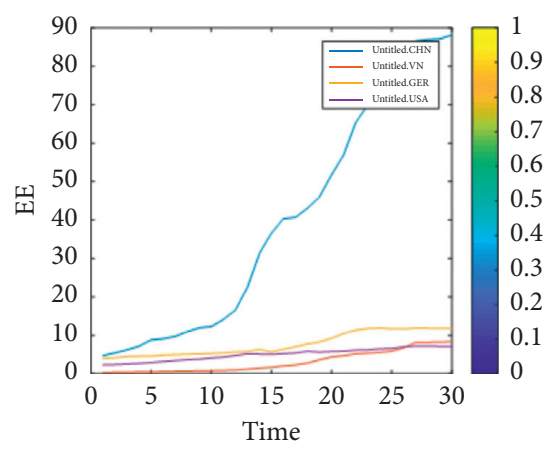

(e)

Figure 5: Comparison of scores of five indicators in different countries.

to this end, the education department in Vietnam must strive to improve the quality of higher education on the basis of meeting the status quo of the construction and expansion of major universities in Vietnam and mainly focus on the graduation rate of college students, the number of college students, and the level of expansion and construction of colleges and universities. Four aspects are improved to meet the development vision of the higher education system in terms of education quality.

(4) Vietnam's Development Vision for Higher Education Funding. According to the following time-series charts of higher education funding in various countries, we can find that, in the past 30 years, education funding in Vietnam and China has continued to rise, and China's education funding has risen much faster than Vietnam, while in the United States and Germany, there is almost no obvious change. However, as a developing country, Vietnam is gradually lower than China in terms of higher education funding, and the gap is getting wider. The lack of funding for higher education in Vietnam is one of the most important reasons hindering the development of higher education in Vietnam.

Regarding the development vision of Vietnam's higher education system in terms of education funds, we believe that Vietnam's education sector should increase funding for higher education in order to alleviate the stagnation of domestic higher education construction and development in recent years. At the same time, higher education involves the country's talent training strategy. Only when the Vietnamese education sector guarantees the need for higher education funds can it make the country's higher education system more complete and meet the vision of higher education construction and development.

(5) The Development Vision of Vietnam's Higher Education Exchange. Through the time-series chart, we can find that, in the past 30 years, both China and Vietnam, as developing countries, have significantly improved the level of higher 
education exchanges in China, while the level of higher education exchanges in Vietnam has not changed significantly. Vietnam's awareness of communicating and learning from other countries in the world is still relatively weak.

Regarding the development vision of Vietnam's higher education system in terms of educational exchanges, we believe that Vietnam's education sector should increase funding for foreign exchanges among college students in order to improve the level of foreign exchanges among Vietnamese colleges and universities, promote domestic colleges and universities to foreign countries, increase the frequency and number of exchanges and learning in universities, and absorb the essence of the development of higher education in foreign universities. By increasing the number of foreign students dispatched and the introduction of outstanding talents from abroad, the level of foreign exchanges in higher education in Vietnam has been improved, so as to meet the development vision of Vietnam in higher education exchanges.

\subsection{Establish the Establishment and Operation of the Evaluation Model for the Healthy and Sustainable Development of the Vietnamese Higher Education System}

4.4.1. Research Ideas. After establishing the health status model of the higher education system, through the evaluation of the five indicators of Vietnam, it is concluded that there is still a large room for improvement in the health status of the current higher education system in Vietnam, and the higher education system in Vietnam has certain deficiencies in the five aspects of education cost, education opportunities, education quality, education exchanges, and education funds. For this reason, we need to make certain adjustments to various indicator data in Vietnam in order to create a set for Vietnam. A healthy sustainability model adapted to the health status of higher education in Vietnam.

Specifically, after obtaining the health evaluation index (EH) of the higher education system for any country, we evaluated the health status of the higher education system in Vietnam and obtained the evaluation index of Vietnam $\left(\mathrm{EH}_{\mathrm{VN}}\right)$. On this basis, we have added an evaluation index $\left(\mathrm{EH}_{\mathrm{DG}}\right)$ based on the health of the higher education system in developing countries. By combining the above evaluation indicators, we have constructed a set of adjusted evaluation indicators for the healthy and sustainable development of Vietnam's higher education system, which we named $\left(\mathrm{REH}_{\mathrm{VN}}\right)$. Among them, the evaluation index model for the healthy and sustainable development of the Vietnamese higher education system is as follows:

$$
E H *\left(\frac{\mathrm{EH}_{\mathrm{DG}}}{\mathrm{EH}_{\mathrm{VN}}}\right)=\mathrm{REH}_{\mathrm{VN}}
$$

where $\mathrm{EH}$ is the evaluation indicators for the health of the higher education system of any country, $\mathrm{EH}_{\mathrm{VN}}$ is the evaluation indicators for the health status of the higher education system in Vietnam, $\mathrm{EH}_{\mathrm{DG}}$ is the evaluation indicators for the health status of higher education systems in developing countries, and $\mathrm{REH}_{\mathrm{VN}}$ is the adjusted evaluation indicators for the healthy and sustainable development of Vietnam's Higher Education System.

4.4.2. Analysis Process. After establishing an evaluation model for the healthy and sustainable development of Vietnam's higher education system, in order to enable the model to be more reasonably and effectively applied to the future development of the Vietnamese higher education system, we will then examine and verify the model. Operation was carried out in order to make appropriate adjustments to the evaluation model and, as far as possible, to obtain the most suitable evaluation model and evaluation indicators for the healthy and sustainable development of the Vietnamese higher education system. The specific idea is shown in Figure 6.

In the specific implementation of the model, we first collected and sorted out the current data of the Vietnamese higher education system and obtained the current health status index of Vietnam's higher education system $\mathrm{EH}_{\mathrm{VN}}$ through the national higher education system health evaluation model. On this basis, we adjust the five indicators of the Vietnamese higher education system, education cost (ES), education opportunity (EC), education quality (EQ), education exchange (EE), and education fund (EF), and apply the healthy and sustainable development evaluation model for the Vietnamese higher education system to assign and adjust various data indicators, thus obtaining the adjusted healthy and sustainable development evaluation index of the Vietnamese higher education system $\left(\mathrm{REH}_{\mathrm{VN}}\right)$.

Next, we test whether the adjusted evaluation index for the healthy and sustainable development of the Vietnamese higher education system $\left(\mathrm{REH}_{\mathrm{VN}}\right)$ and its model meet the healthy and sustainable development of the Vietnamese higher education system. When the test results show that the evaluation indicators and models meet the healthy and sustainable development of the domestic higher education system in Vietnam, the indicators and models can be applied to the Vietnamese higher education system. If the model test results show that the evaluation indicators and models do not meet the needs of Vietnam with the development of the domestic higher education system, this indicator can be reassigned and adjusted. As the number of adjustments of the evaluation index in the model increases, the more likely it is that the final evaluation index will meet the future healthy development of the Vietnamese higher education system.

After adjustment, we get the new weights of the five indicators, as shown in Table 5.

We integrated the weights of five first-level indicators, education cost (ES), educational opportunity (EC), education quality (EQ), educational exchange (EE), and educational funds (EF), and finally obtained the country's higher evaluation mathematical model of the health of the education system as follows: 


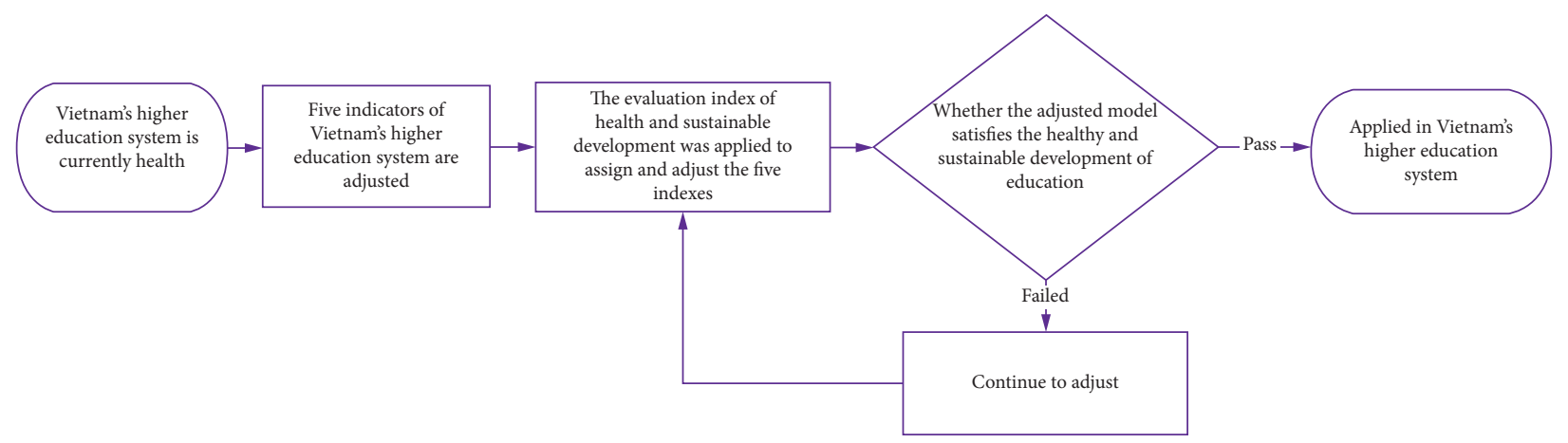

FIGURE 6: Flowchart of model operation process.

$$
\begin{aligned}
\mathrm{VNEH}= & 0.483 \mathrm{ES}+0.182 \mathrm{EF}+0.156 \mathrm{EE} \\
& +0.175 \mathrm{EC}+0.209 \mathrm{EQ} .
\end{aligned}
$$

Among them, VNEH is an evaluation index of the health status of the Vietnamese higher education system, that is, the health of Vietnamese higher education. ES, EC, EQ, EE, and $\mathrm{EF}$ are five indicators.

\subsection{Education Policy Recommendations and Implementation Timetable for Vietnam}

4.5.1. Analysis of the Development Trend of the Health of Vietnam's Higher Education Based on the ARMA Model

(1) ARMAModel Introduction. The ARMA model (autoregressive and moving average model) is an important method for studying time series. It is composed of an autoregressive model (referred to as AR model) and a moving average model (referred to as MA model) based on "hybrid." We regard the data sequence formed by the predictive indicators over time as a random sequence. The dependence of this group of random sequences reflects the continuity of the original data in time. At the same time, we assume that the influencing factors are used for regression analysis:

$$
Y=\beta_{0}+\beta_{1} x_{1}+\beta_{2} x_{2} \cdots \beta_{k} x_{k}+e,
$$

where $Y$ is the observed value of the prediction object and $e$ is the error. As the prediction object, it is affected by its own variables, and its law can be reflected by the following formula:

$$
Y=\beta_{0}+\beta_{1} x_{\mathrm{t}-1}+\beta_{2} x_{\mathrm{t}-2} \cdots \beta_{k} x_{t-p}+e .
$$

The error term has a dependent relationship in different periods and is expressed by the following formula:

$$
e_{t}=\alpha_{0}+\alpha_{1} e_{t-1}+\alpha_{2} e_{t-2} \cdots+\alpha_{q} e_{t-q}+u_{t} .
$$

From this, we obtain the ARMA model expression:

$$
\begin{aligned}
Y_{t}= & \beta_{0}+\beta_{1} x_{t-1}+\beta_{2} x_{t-2} \cdots \beta_{k} x_{t-p}+\alpha_{0} \\
& +\alpha_{1} e_{t-1}+\alpha_{2} e_{t-2}+\cdots+\alpha_{q} e_{t-q}+u_{t} .
\end{aligned}
$$

TABLE 5: Health weights of higher education in Vietnam.

\begin{tabular}{lccccc}
\hline Index & ES & EF & EE & EC & EQ \\
\hline Current weight & 0.483 & 0.182 & 0.156 & 0.175 & 0.209 \\
\hline
\end{tabular}

(2) Analysis on the Development Trend of the Health of Higher Education in Vietnam. The use of the ARMA model requires that the time series must be stable, and the original data needs to be tested for stationarity. Inspection methods include ADF, KPSS, and P-P. Here, ADF test and KPSS test are used, and yd1_h_adf $=1$ and yd1_h_kpss $=0$ are obtained, and the test is passed. The time-series forecast graph and time-series forecast table are obtained by running the model $[13,14]$, as shown in Figure 7 and Table 6.

From the time-series forecast table, it can be seen that the health of Vietnamese universities is gradually increasing, showing an upward trend. According to the health expectations of Vietnamese colleges and universities determined above, combined with the analysis of the time series forecast table, Vietnam's health expectations for colleges and universities in 2025 are 8.52, which has exceeded the health expectations of Vietnamese colleges and universities of 8.3, indicating that Vietnam has already realized the reasonable and expected vision previously preset, exceeding the average level of health of universities in developing countries in the world. Therefore, the implementation timetable limit is 5 years; within 5 years is the adjustment catch-up period, and after 5 years is the consolidation development period.

4.5.2. Policy and Implementation Timeline Analysis of the Development Trend of Education Health. In view of the current development status of the Vietnamese higher education system, we have put forward targeted development policies and corresponding policy implementation timetables for the future development of Vietnamese higher education and specifically included education costs (ES), educational opportunities (EC), education quality (EQ), education exchange (EE), and education funds (EF); these five aspects are the future implementation directions of Vietnam's higher education policy. In terms of the time period for policy implementation, we choose from 2021 to the time period for implementing Vietnam's higher 


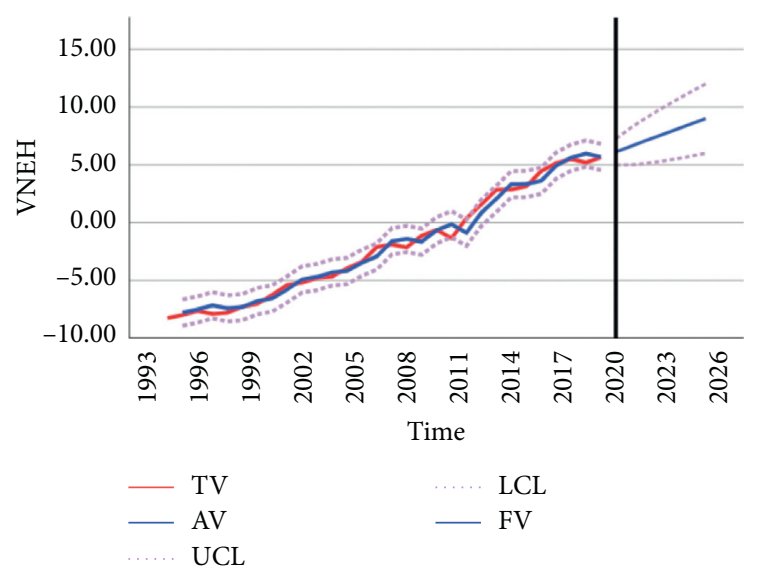

FIgURE 7: Time-series forecast.

TABLe 6: Time-series forecast table.

\begin{tabular}{ccccccccc}
\hline Model & & 2020 & 2021 & 2022 & 2023 & 2024 & 2025 & 2026 \\
\hline \multirow{3}{*}{ VNEH } & FV & 6.12 & 6.60 & 7.08 & 7.56 & 8.04 & 8.52 & 9.00 \\
& UCL & 7.26 & 8.21 & 9.05 & 9.83 & 10.58 & 11.30 & 12.00 \\
& LCL & 4.99 & 5.00 & 5.11 & 5.29 & 5.50 & 5.74 & 6.00 \\
\hline
\end{tabular}

Note: for each model, the prediction starts after the last nonmissing value in the range of the requested estimation period and ends at the last period in which all predictors have available nonmissing values or at the end of the requested prediction period. The date ends, whichever is earlier.

education policy in 2025, and the specific timeline of targeted policy implementation is shown in Figure 8.

(1) Implementation Policy on Education Cost. Regarding Vietnam's implementation of policies on higher education costs, we believe that relevant government departments in Vietnam should increase their control over the cost of higher education in 2021 and establish a complete cost accounting system for higher education so that they can provide assistance to government departments. Save certain educational resources and educational costs. At the same time, government departments should also increase their investment in education costs, so as to provide sufficient funding sources for the government's education construction and improve the utilization rate and efficiency of higher education costs in Vietnam.

(2) Implementation Policy on Educational Opportunities. Regarding Vietnam's policy on higher education opportunities, we believe that Vietnam's education sector will implement the policy in 2022. In terms of policy implementation, it is necessary to allocate students' educational opportunities in higher education in a reasonable and effective manner so that certain domestic inequalities in education can be reduced. Furthermore, the relevant legislative bodies in Vietnam can also formulate corresponding laws and regulations on higher education entrance opportunities, so as to regulate the domestic higher education entrance system in Vietnam, and provide a more fair way for Vietnamese students in higher education such as equal access to education.
(3) Implementation Policy in Education Quality. With regard to the implementation of policies on the quality of higher education in Vietnam, we believe that relevant universities and education departments in Vietnam should implement relevant policies in 2023. Specifically, the major universities in Vietnam can strengthen the construction of the school's ethics and morals. Improve the quality of teachers at the higher education level. Furthermore, government departments should also strengthen the management of higher education rules and regulations so that related higher education systems can be more standardized and rationalized. Finally, Vietnam's domestic education departments and university teachers should also strengthen classroom management of universities and strictly regulate the development process of university classrooms, so as to improve the quality of higher education development at the root.

(4) Implementation Policies for Education Funds. With regard to the implementation of Vietnam's higher education funding policy, we believe that relevant government departments in Vietnam can initiate higher education funding policies in 2024. First of all, government departments can provide sufficient funding sources for the development of higher education in Vietnam by increasing government funding. Secondly, the domestic education department in Vietnam can attract foreign capital to invest in the domestic higher education system by issuing relevant preferential policies and education development policies, thereby expanding the funding sources for the construction and development of higher education in Vietnam and to a certain extent reduce the pressure on capital supply in Vietnam's domestic education sector.

(5) Implementation Policies for Educational Exchanges. With regard to the implementation of Vietnam's higher education exchange policies, we believe that Vietnamese universities and government departments can implement relevant higher education exchange policies in 2025. First of all, Vietnamese government departments can provide certain opportunities for foreign exchanges for teachers and students in domestic universities and encourage them to exchange and study abroad and, at the same time, provide certain financial assistance for university teachers and students. Furthermore, Vietnamese universities can appropriately encourage students to study abroad, thereby increasing the number of international students in Vietnamese universities and enhancing the overall level of higher education exchanges. Finally, some colleges and universities in Vietnam can reach agreements with foreign colleges and universities on regular learning exchanges, so as to enhance the continuity and coherence of the Vietnamese higher education system in foreign education exchanges.

\subsection{Evaluation of the Effectiveness of Education Policies}

4.6.1. Sensitivity Test of the Adjusted Healthy and Sustainable Development Model of Higher Education in Vietnam. We have established a healthy and sustainable development 


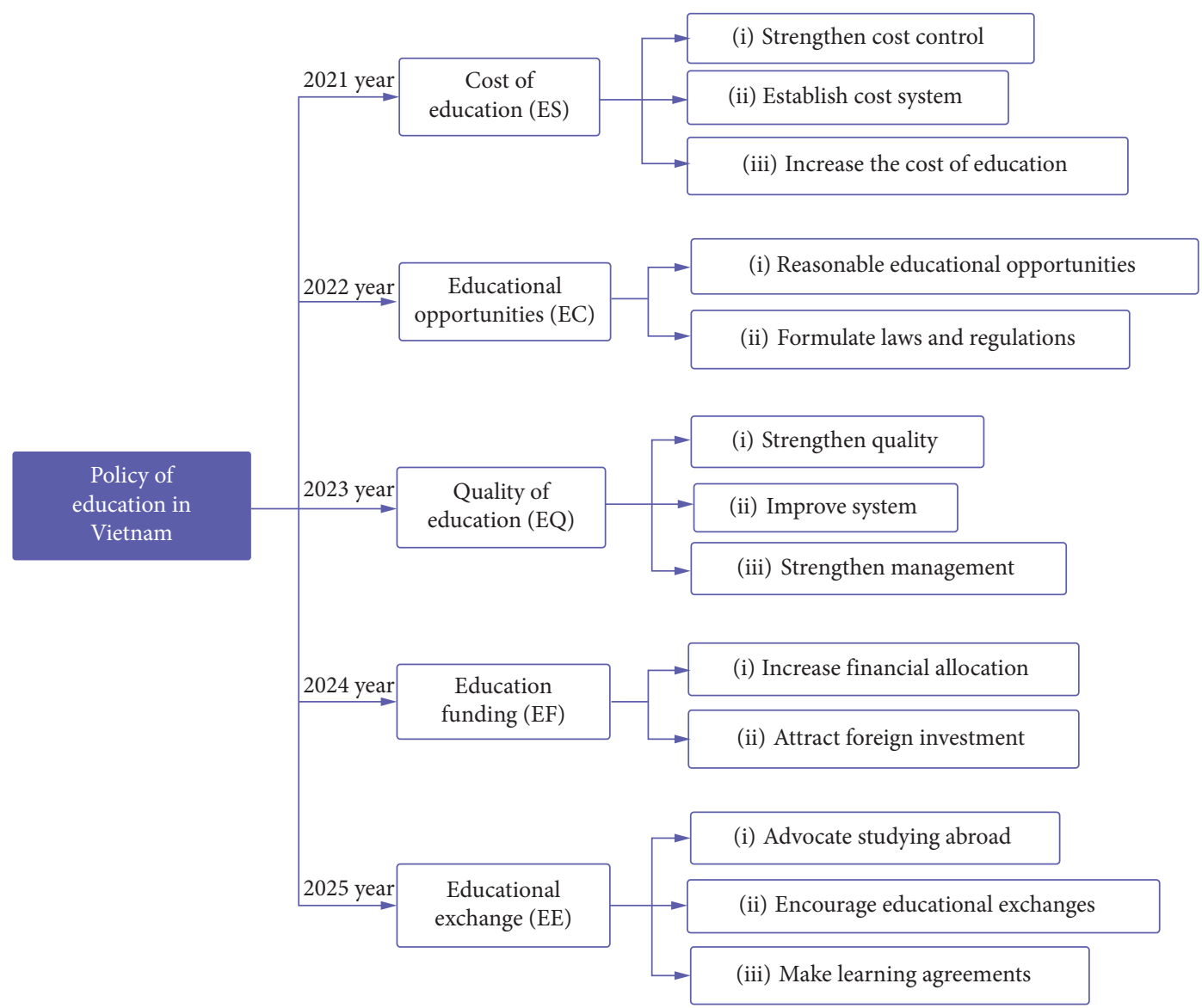

FIGURE 8: Timeline of Vietnam higher education policy implementation.

evaluation indicator model for the Vietnamese higher education system and substituted the data corresponding to the five indicators of Vietnam's education cost, education opportunities, education quality, education funds, and education exchanges into the model for calculation. After many index adjustments, a suitable model was obtained for the healthy and sustainable development of the Vietnamese higher education system in the future after the weight of each index was assigned. The model is shown below:

$$
\begin{aligned}
\mathrm{REH}_{\mathrm{VN}}= & 0.483 \mathrm{ES}+0.182 \mathrm{EF}+0.156 \mathrm{EE} \\
& +0.175 \mathrm{EC}+0.209 \mathrm{EQ} .
\end{aligned}
$$

Based on the established evaluation model of the healthy and sustainable development of the Vietnamese higher education system, we set that when other variables are constant, the health of Vietnamese higher education will vary with the added value of the education cost (ES), use MATLAB software to perform sensitivity, and analyze and evaluate the effectiveness of Vietnam's higher education system policy.

Based on the above sensitivity analysis in Table 7 and using mathematical software, we further produced a sensitivity analysis map of the health status of higher education in Vietnam. The result is as shown in Figure 9.

It can be seen from the figure that when the cost of higher education (ES) in Vietnam is determined to be constant, changes in the parameter values will cause changes in the evaluation index for the healthy and sustainable development of the Vietnamese higher education system, and the amount of change will increase with the increase in the average task distance increase. When the parameter value is constant, the value increases with the increase of the ES value, and we get the conclusion that the adjusted healthy and sustainable development model of the Vietnamese higher education system has passed the sensitivity analysis.

4.6.2. Testing the Effectiveness of Vietnam's Higher Education Policy Implementation. In order to be able to better evaluate the policy implementation effects of the policies and measures proposed by Vietnam and the development of higher education, we have conducted a corresponding test on the effectiveness of the implementation of the Vietnamese higher education policy. The results of the policy effectiveness test are shown in Figure 10.

We can know from the results of the effectiveness test of the policy that, before the implementation of the policy, the level of domestic higher education development in Vietnam has shown a continuous rise, and Vietnam has implemented the abovementioned education costs, education exchanges, and education funds. After the five policy measures of education quality and educational 
TABLE 7: Values calculated under different higher education costs $\left(\mathrm{REH}_{\mathrm{VN}}\right)$.

\begin{tabular}{|c|c|c|c|c|c|c|c|c|c|}
\hline ES & 1.4 & 1.6 & 1.8 & 2.0 & 2.2 & 2.4 & 2.6 & 2.8 & 3.0 \\
\hline $\mathrm{REH}_{\mathrm{VN}_{1}}$ & 1.769 & 1.8656 & 1.9622 & 2.0588 & 2.1554 & 2.252 & 2.3486 & 2.4452 & 2.5418 \\
\hline $\mathrm{REH}_{\mathrm{VN}_{2}}$ & 1.797 & 1.8976 & 1.9982 & 2.0988 & 2.1994 & 2.3 & 2.4006 & 2.5012 & 2.6018 \\
\hline $\mathrm{REH}_{\mathrm{VN}_{3}}$ & 1.825 & 1.9296 & 2.0342 & 2.1388 & 2.2434 & 2.348 & 2.4526 & 2.5572 & 2.6618 \\
\hline $\mathrm{REH}_{\mathrm{VN}_{4}}$ & 1.853 & 1.9616 & 2.0702 & 2.1788 & 2.2874 & 2.396 & 2.5046 & 2.6132 & 2.7218 \\
\hline $\mathrm{REH}_{\mathrm{VN}_{5}}$ & 1.881 & 1.9936 & 2.1062 & 2.2188 & 2.3314 & 2.444 & 2.5566 & 2.6692 & 2.7818 \\
\hline $\mathrm{REH}_{\mathrm{VN}_{6}}$ & 1.909 & 2.0256 & 2.1422 & 2.2588 & 2.3754 & 2.492 & 2.6086 & 2.7252 & 2.8418 \\
\hline
\end{tabular}

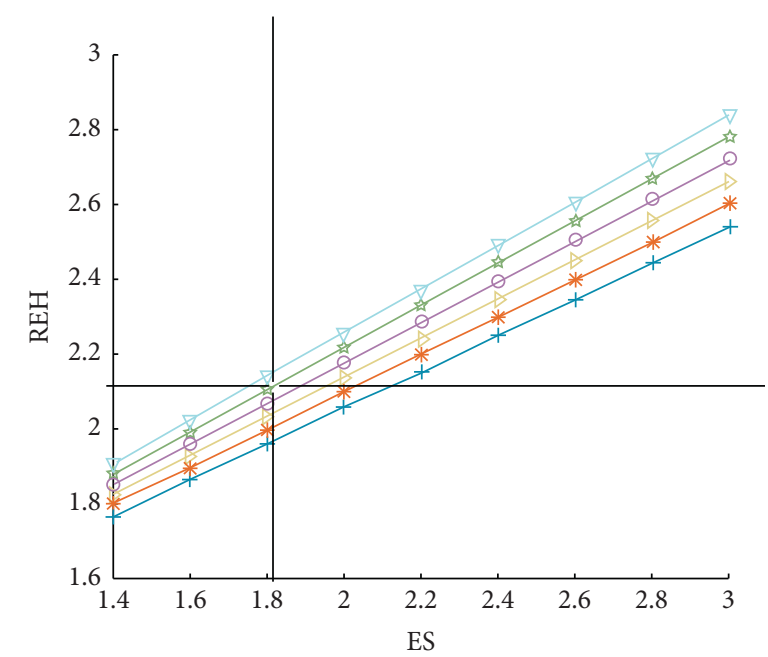

Figure 9: Sensitivity analysis of the health status of higher education in Vietnam.

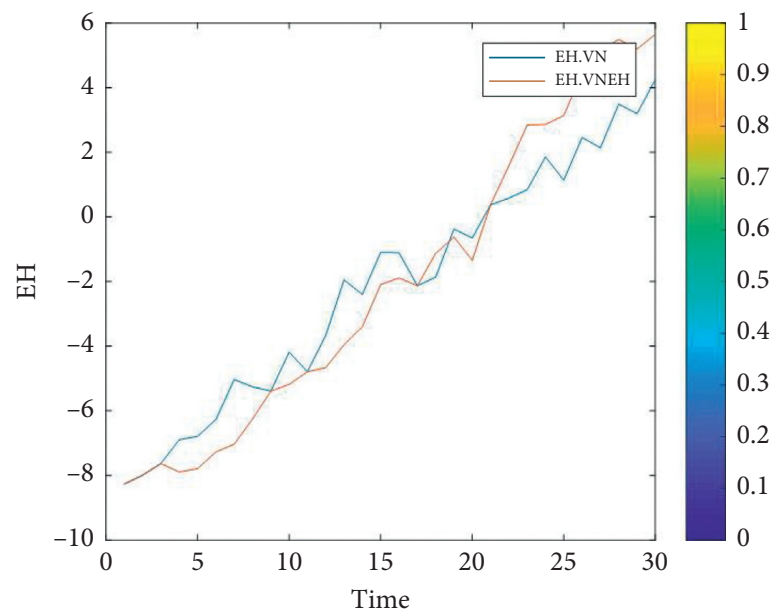

Figure 10: Test results of the effectiveness of Vietnam's higher education policy.

opportunities, the development level of Vietnam's higher education system will exceed the original development level of higher education in the future. At the same time, the development speed of higher education in Vietnam will maintain a rapid growth on this basis, which indicates that, after implementing relevant development policies, the higher education system in Vietnam will enter a stage of healthy and sustainable development. This, on the contrary, also proves that the development policies for Vietnam's higher education system proposed in the previous article are effective.
4.7. Analysis of the Impact of Policy Implementation. Implementing our plan for the higher education system in Vietnam, both in the process of implementation and in the final result, will have a huge impact on our real world. The impact is mainly manifested in five aspects: students, teachers, schools, communities, and the country [15-20].

4.7.1. Student Level. Learning method: the implementation of the new education policy will change the learning style of students. Students with different goals will learn in different 
ways, which will be different from the traditional education model. Self-positioning: under the new systematic education policy, students will have a comprehensive understanding of themselves, and they will determine their own position based on their own strengths. The original shortcomings in learning can be infinitely reduced by covering up their strengths. Clearly understand the direction you are learning on this path.

4.7.2. Teacher Level. Teaching role: in traditional education, the relationship between teachers and students is always humble, but under the new education policy, the role of teachers will change and they will gradually integrate into teaching as friends. Teachers will also be facilitators of students, researchers of teaching results, and creators of curriculum development. Teaching behavior: teachers will learn from each other, improve each other, and respect and appreciate each other in the education process. When encountering a problem, the teacher will inspire the thinking of the students in a guiding way, no longer directly tell the students the answer to the question, emphasize thinking about the problem, and reflect on the problem.

4.7.3. School Level. Purpose: the school will train talents in a targeted manner according to the implementation goals of the new education system and set up training plans for talents in different aspects. When college students graduate, check whether the students meet the school's graduation standards. If they fail to meet the school's requirements, the students will continue to study until they complete the school's professional tasks. According to the new education system policy, schools will set up individualized talent training programs for students, making different schools have unique personalization. In the past education policy, the school paid more attention to the graduation rate of students and did not consider the real demand for a degree from the perspective of students.

4.7.4. Community Level. Enrich community education services: community education services will become rich and colorful, such as simple educational knowledge contests and educational presentation activities, will be launched in the community one by one. Promote the sustainable development of community education. A complete education system will allow the continuous development of community education, and once the education policy affects the community, the citizens of the entire community will be affected and gradually join the educational activities, and the life of every community citizen will also be affected.

4.7.5. Country Level. Improve the quality of students: the new education policy will improve the quality of students, study exchanges in colleges and universities, and allow students to get along with qualified talents. The so-called: "the ones who are close to Zhu are red and those who are close to ink are black." Over time, the quality of most students improves. Cultivate scientific and technological talents: under the implementation of the new education policy, the country will pay more attention to the cultivation of scientific and technological talents. Scientific and technological talents are an important force in the country's development and will also be the target of efforts to train in future education. Promote national development: the implementation of the new policy will promote the development of the entire country. Youth are the saplings of the motherland. Under the cultivation of national education, they will become towering trees to carry the important task of national development.

Even if the results of the implementation have a satisfactory impact on the entire real world, we still have to realize that change is not a simple matter during the whole process. The whole change road is full of setbacks and thorns.

\section{Conclusion}

By establishing a health evaluation model of the national higher education system and applying the model to specific developed and developing countries, after analysis and comparison, we choose Vietnam as a country whose higher education system needs improvement and put forward an achievable and reasonable development vision in the future based on the current development of higher education in Vietnam. Next, a health sustainability evaluation model for the Vietnamese higher education system is established, and various indicators of Vietnam are adjusted by this model, and then, the health evaluation indicators that meet the future sustainable development of the Vietnamese higher education system are obtained.

Furthermore, the ARMA model is used to predict the future development of the Vietnamese higher education system, and specific policy recommendations and implementation timetables for related policies are given based on the future development of the Vietnamese higher education system. At the same time, sensitivity analysis and validity test were used to evaluate the validity of the model and policy. Finally, according to the application effect of the model and policy, the impact of the plan formulated during the transition period and the final state on the actual development of the higher education system in Vietnam is discussed.

\section{Data Availability}

The data used to support the findings of this study are included within the article.

\section{Conflicts of Interest}

The authors declare that there are no conflicts of interest regarding the publication of this paper.

\section{Acknowledgments}

This study was funded by the General Project of Philosophy and Social Science Planning of Anhui Province: Research on Government R\&D Subsidies Promoting Green Innovation Efficiency of Anhui High-Tech Industries (no. 
AHSKY2019D085), Teaching and Research Fund Project of the Education Department of Anhui Province (2020jyxm0017 and 2018jyxm1305), "First-class Course" of Anhui University of Finance and Economics (acylkc202008), and Teaching and Research Fund Project of the Anhui University of Finance and Economics (acjyyb2020011 and acjyyb2020014).

\section{References}

[1] T. Liu and J. Z. Yang, "Research on learning evaluation of higher education based on block chain technology," Software Guide, vol. 19, no. 5, pp. 242-246, 2020.

[2] H. L. Wang and Z. Y. Li, "Research on the review and evaluation of British higher education based on the concept of risk," Modern Educational Management, vol. 38, no. 1, pp. 62-66, 2018.

[3] H. Zhao and L. J. Guan, "Research on sustainable development of higher education in China based on IFE and EFE matrix," Modern Educational Management, vol. 36, no. 9, pp. 87-92, 2016.

[4] Q. Li, "Higher education efficiency evaluation based on super efficiency DEA model," Heilongjiang Higher Education Research, vol. 34, no. 9, pp. 153-156, 2015.

[5] Y. D. Zhu, X. H. Xiang, and Y. J. Ye, "Research on the comprehensive evaluation of the development level of American higher education based on factor analysis," Exploration of Higher Education, vol. 30, no. 5, pp. 68-73, 2014.

[6] J. Z. Xu and Y. B. Li, "Higher education resource integration evaluation based on DEA," Journal of Harbin Engineering University, vol. 28, no. 4, pp. 469-473, 2007.

[7] P. Wang, F. M. Kuang, Y. W. Deng, Y. P. Tian, and F. Yi, "Evaluation of land ecological security in Hengyang City based on principal component analysis," Economic Geography, vol. 35, no. 1, pp. 168-172, 2015.

[8] A. Huang, L. Yang, T. Du, A. Wang, B. Zhang, and G. Yuan, "Comprehensive evaluation of soil nutrients based on principal component analysis," Arid Zone Research, vol. 31, no. 5, pp. 819-825, 2014.

[9] P. Chen, "Research on principal component analysis and its application in feature extraction," Shaanxi Normal University, vol. 20, no. 2, pp. 1-65, 2014.

[10] X. Wang, Y. H. Wang, L. Su, B. Guo, and S. W. Wang, "Construction and evaluation of production-city integration index system of national high-tech zones based on factor analysis and entropy method," Science of Science and Management of Science and Technology, vol. 35, no. 7, pp. 79-88, 2014.

[11] F. X. Wang, A. H. Mao, H. L. Li, and M. L. Jia, "Quality measurement and spatial difference analysis of urbanization in shandong Province based on entropy method," Scientia Geographica Sinica, vol. 33, no. 11, pp. 1323-1329, 2013.

[12] Y. Wang, X. Cheng, P. H. Yin, and X. H. Zhang, "Research on regional characteristics affecting carbon emission performance in China: a cluster analysis based on entropy method," Journal of Natural Resources, vol. 28, no. 7, pp. 1106-1116, 2013.

[13] Y. J. Yan, G. H. Sheng, Y. F. Chen, X. C. Jiang, Z. H. Guo, and S. P. Qin, "Big data cleaning method of power transmission and transformation equipment state based on time series analysis," Automation of Power Systems, vol. 39, no. 7, pp. 138-144, 2015.
[14] X. Wang, "Research on network security situation prediction model based on time series analysis," Beijing University of Posts and Telecommunications, vol. 23, no. 8, pp. 1-60, 2015.

[15] H. Q. L. Ruan, "Research on the current situation and countermeasures of higher education development in Vietnam," Southeast Asia Review, vol. 35, no. 6, pp. 50-54, 2014.

[16] Nguyenkhachung, "Comparative study on higher education reform between China and Vietnam," East China Normal University, vol. 18, no. 11, pp. 1-195, 2014.

[17] Y. K. Ou, "New strategy of Vietnam's education development in the 21st century: ideas, goals and strategies," Foreign Education Research, vol. 38, no. 11, pp. 13-17, 2011.

[18] Z. W. Shang, "Characteristics and trends of Vietnam's education policy in the early 21 st century," Southeast Asia, vol. 32, no. 10, pp. 9-12, 2011.

[19] J. B. Yang, "Some reforms and achievements of general secondary education in Vietnam since the 21st century," Foreign Primary and Secondary Education, vol. 29, no. 10, pp. 48-52, 2010.

[20] F. Z. Yu, "Current situation and prospect of education in Vietnam," Southeast Asia, vol. 23, no. 9, pp. 37-40, 2002. 